Mens-Verhulst, J. van, Bensing, J. Distinguishing between chronic and nonchronic fatigue, the role of gender and age. Social Science \& Medicine: 1998, 47(5), p. 621-634

\begin{tabular}{|l|l|}
\hline $\begin{array}{l}\text { Postprint } \\
\text { Version } \\
\text { Journal website }\end{array}$ & 1.0 \\
\hline Pubmed link & $\underline{\text { http:///ww.doi.org/10.1016/S0277-9536(98)00116-6 }}$ \\
\hline DOI & $10.1016 / \mathrm{S} 0277-9536(98) 00116-6$ \\
\hline
\end{tabular}

This is a NIVEL certified Post Print, more info at http://www.nivel.eu

\title{
DISTINGUISHING BETWEEN CHRONIC AND NONCHRONIC FATIGUE, THE ROLE OF GENDER AND AGE
}

\author{
JANNEKE VAN MENS-VERHULST ${ }^{1 *}$ AND JOZIEN BENSING ${ }^{2,3}$
}

1Department of Clinical and Health Psychology, Utrecht University, Postbox 80140, 3508

TC Utrecht, The Netherlands, 2 Research School Psychology and Health, Utrecht University, Utrecht, The Netherlands and ${ }_{3}$ Netherlands Institute of Primary Health Care (NIVEL), Utrecht University, Utrecht, The Netherlands

*Author for correspondence.

\begin{abstract}
In this study the authors try to clarify the ambiguities in previous studies on demographic and social factors and fatigue. We have divided people with fatigue complaints and associated symptoms into those who have chronic and non-chronic complaints, and into men and women. The research is based on diaries kept by Dutch citizens over a 21-day period, and uses univariate and discriminant analyses. The results show the utility of stratification for chronicity, gender and age. Compared to nonchronically fatigued subjects (NCFd) the chronically fatigued subjects (CFd) reveal multiple sources of vulnerability: physical, psychological, psycho-social and socio-economic. They report more days of fatigue, they tend to be older, and their physical health is characterized by significantly more acute complaints and chronic disease. Their sum scores on psychological and psycho-social problems are above average. Their health histories are worse, they express greater feelings of frustration and irritation due to their ailments and report more health-related initiatives. The socio-economic profile of the CFd is disadvantaged: their educational level, occupational classification and income are lower than that of the NCFd, and they are more frequently unemployed. CFd women are more frequently divorced or widowed than NCFd women. The factors predicting chronic vs non-chronic fatigue vary with the age and gender of the population. It is easier to predict non-chronic than chronic fatigue. Additional stratification within the group of CFd is recommended. (C) 1998 Elsevier Science Ltd. All rights reserved
\end{abstract}

\section{INTRODUCTION}

Fatigue is one of those complaints for which a biomedical etiology can seldom be found (Morrison, 1980; Sugarman and Berg, 1984; Knottnerus et al., 1986; Kroenke et al., 1988; Pennincks, 1991; Ridsdale et al., 1993). It is known to be the unwelcome companion of many chronic diseases (Chen, 1986; Lewis and Wessely, 1992; Bensing et al., 1996). Fatigue is also substantially related to psychological morbidity (Chen, 1986; Kroenke et al., 1988; Tibblin et al., 1990; Ridsdale et al., 1993; Pawlikowska et al., 1994).

The contribution of demographical and social factors to fatigue is still unclear. The results of available studies on sex and age are often contradictory. Most community studies suggest that fatigue is more prevalent among women, even after adjustment for psychological 
Mens-Verhulst, J. van, Bensing, J. Distinguishing between chronic and nonchronic fatigue, the role of gender and age. Social Science \& Medicine: 1998, 47(5), p. 621-634

distress (Pawlikowska et al., 1994). Depending on the study, fatigue is found to be considerably more prevalent among women (Chen, 1986; De Bakker et al., 1992) or modestly to significantly more prevalent (Lawrie and Pelosi, 1995). However, if fatigue is differentiated by persistence the overrepresentation in women tends to disappear (Ridsdale et al., 1993) or even to reverse (Van Mens-Verhulst and Bensing, 1997). Lewis and Wessely (1992) observe that although fatigue is two to three times more prevalent in women than in men, "the more homogeneous the study, the less the difference".

Contradictory results are also found in the relationship between age and fatigue. Some authors found no correlations (Sugarman and Berg, 1984; Chen, 1986; Valdini et al., 1988; Ridsdale et al., 1993). Others have found inverse correlations (Tibblin et al., 1990) or positive but weak correlations if the duration of the fatigue was taken into account (David et al., 1990). Additionally, the inverse correlation was established as being only for women by Cox et al. (1987), and the positive correlation as being only for women between 18 and 45 years old by Pawlikowska et al. (1994).

The interaction between age and sex in relation to fatigue has been found to be very weak (Pawlikowska et al., 1994), non-existent (Kirk et al., 1990), or fairly significant when the subjects are classified as older or younger than 45 years of age (David et al., 1990).

The ambiguity with regard to the role of demographic factors in chronic fatigue may be due to methodological differences in the studies. Fatigue can not only vary from a common condition which everybody experiences now and then to a serious and persistent health problem with major consequences for the quality of life. It is also multidimensional in that it has been shown to involve both physical and mental dimensions (Vertommen and Leyssen, 1988; David et al., 1990; Ray et al., 1992; Chalder et al., 1993; Smets et al., 1995).

Moreover, various demographic, social, psychological and medical factors may interact to make the attainment of clear findings with regard to fatigue most difficult. It may therefore be helpful to compile samples which are homogeneous with respect to the factors that are thought to be influential and have been found to be indeterminate.

The present study was designed to clarify the inconsistencies in epidemiological findings by stratification for fatigue duration, gender and age. Firstly, the null hypothesis was tested that no differences in social, psychological and physical factors would exist between people with long-term vs people with short-term fatigue complaints. Secondly, the null hypothesis was tested on the male and female population separately thus applying a gender perspective from which the social, psychological and physical dimensions are systematically analyzed (Adesso et al., 1994; Leventhal, 1994). Thirdly, confirmation of the stratification was sought by looking for the predictability of the different gender and age groups, and for possible differences in their predictors.

\section{METHODS}

\section{Procedure and sample}

The data used in this study are from the Dutch National Survey of General Practitioners (DNSGP), undertaken in 1987-1988 by the Netherlands Institute for Primary Care (NIVEL). The people surveyed were selected from the rolls of 161 general practitioners who were organized in 103 practices. A non-proportional stratified sample of 17,344 people was approached. The stratification variables were: region, level of urbanization and distance to a hospital. This group also included patients who had not visited their GP for a long time. (Van der Velden et al., 1992). Via a letter from their GP at their home address the people in this group were asked to take part in an extensive health interview. In order to motivate participation in the survey, an announcement was also made in local house-to-house circulars or newspapers, sometimes accompanied by a photo or an interview with the participating doctor. 13,066 participants agreed to be interviewed.

As almost everybody in the Netherlands is listed with a GP, the sample was reasonably representative of the Dutch population. There was a slight over-representation of citizens 
Mens-Verhulst, J. van, Bensing, J. Distinguishing between chronic and nonchronic fatigue, the role of gender and age. Social Science \& Medicine: 1998, 47(5), p. 621-634

between 25 and 44 years of age, and a slight under-representation of citizens older than 65 . The non-response rate ( $24 \%$ of the original sample) appeared to be due to people's incapacity or lack of motivation (52.8\%) and inaccessibility (41.8\%) (Foets and Sixma, 1991).

At the end of the interview the participants were asked to keep a health diary for 21 days. If they agreed, and 11,038 of them did (85\%), the interviewer made an appointment to pick up the diary. During the diary-keeping period the interviewer phoned twice to check if there were any problems. Only fully completed diaries were processed; the degree of compliance and precision proved to be reasonable; and the resulting database contained 8524 cases.

\section{Instruments}

The extensive health interview consisted of 189 questions and several questionnaires and checklists with regard to psychological and psycho-social problems, life events, acute complaints and chronic diseases. For each list, a sum-score of the number of problems or events was constructed.

The General Health Questionnaire (GHQ) is a screening instrument for psychiatric illness that offers insight into acute psychiatric symptoms - referred to here as psychological problems - but does not measure neuroticism as personality trait (Goldberg, 1972; Furer and Tax, 1987). The questionnaire is based on respondents experiences in the previous four weeks. The 30-item version was used. Women and lower educated people are known to score higher on the GHQ than men and higher educated people (Goldberg, 1978).

The Biographic Problem List (BIOPRO) contains 22 questions with regard to possible psycho-social problems in a variety of life areas (finances, partner, children, sexuality or leisure time, for instance). Respondents can answer "yes", "no" or "does not apply" (Foets and Van der Velden, 1990; Vermande and Bijl, 1995) and thereby indicate their psychosocial state at the moment of the interview. (Furer and Tax, 1987; Tijhuis, 1994). Its scaling properties have been found to be satisfactory. In a panel study of psycho-social problems, the Cronbach's alphas were found to be 0.76 and 0.78 for the first and second waves, respectively. On the basis of previous studies it can also be assumed that a simple counting of problems will strongly correlate with indicators of distress (Kooiker, 1995). Screening did not reveal a sex bias (Vereijken and Bauduin, 1992).

The checklist assessing stressful life-events contains 34 items known for their potential impact on psychological stability. Examples are a financial windfall or disappointment; moving; the birth or departure of a child; loss of a loved one (person or animal); initiation, completion or termination of education; abuse; a lawsuit; or hospitalization. The answer could be "yes" or "no" with reference to a period of a year (Tijhuis, 1994).

The Symptom Check List measuring acute complaints was originally developed for physicians to estimate the severity of daily symptoms but was modified to study such symptoms at the community level (Kooiker, 1996). The checklist contains 42 symptoms ranging from having a cough to pain attributed to the heart and includes an item pertaining to fatigue. The checklist also contains three open-ended items for information with regard to additional complaints. The response options are "yes" or "no" with the previous fortnight as reference period (Foets and Van der Velden, 1990; Kooiker, 1995).

The checklist addressing the presence of chronic conditions covers 25 diseases of varying severity and contained three 3 open-ended items for additional diseases. The respondent had to fill in whether he or she su.ered from this condition and if so, since when. The list is based on a previous study from Van den Bos et al. (1986) and contains almost all of the chronic ailments that are considered to have fatigue as comorbidity (Chen, 1986; Lewis and Wessely, 1992; Bensing et al., 1996): headache; hypertension; rheumatism; stomach and bowel problems; thyroid disorders; prostate or menstrual problems; bronchitis or asthma; heart problems; multiple sclerosis and other nervous disorders; renal diseases; and cancer. The following dimensions were used to categorize the diseases as having mild, moderate or severe social consequences: social visibility of the disease for others, threat to others and 
Mens-Verhulst, J. van, Bensing, J. Distinguishing between chronic and nonchronic fatigue, the role of gender and age. Social Science \& Medicine: 1998, 47(5), p. 621-634

degree of functional disablement. Such classification has been successfully employed in a previous GP study (Van de Lisdonk, 1985; Tijhuis, 1994).

With regard to the last four checklists no screening for sex bias has yet been undertaken. However, Sonsbeek (1996) has recently reported that background characteristics such as age, sex or educational level do not produce different responses for instruments comparable to the ones used in the NIVEL health interview.

The design of the diary study was derived from the same GP study (Van de Lisdonk, 1985). A sample diary page can be found in Fig. 1. Participants could record their day-to-day health condition by indicating their state of well-being on a 5-point scale with regard to health experience, activity level and mood and by describing their complaints in their own words. Subsequently they could assess these complaints and register their health actions. It was possible to register two chief complaints (or clusters of complaints) and health-related actions per day.

The complaints were coded by (para-)medically trained personnel as fitting into one of the 97 categories based on a refinement of the International Classification for Primary Care (Lamberts and Wood, 1987). Criteria for refinement of the categories were: high prevalence or incidence, policy relevance, clinical homogeneity and etiological grounds (Foets and Van der Velden, 1990; Van der Velden et al., 1992).

\section{[FIGURE 1]}

\section{Subjects}

Two of the coding categories were relevant for our study of fatigue. The first category pertained to fatigue, tiredness, lack of energy, sleeplessness, nervousness, tension, stress, lack of concentration and forgetfulness. A total of 1135 respondents above the age of 25 reported such fatigue. The second category pertained to psychiatric illness with fatigue as comorbidity clustered with anorexia nervosa, depression, neurosis, psychosis and mental problems. A total of 77 respondents reported such fatigue. As fatigue was the central complaint in the first category and the latter category included relatively few respondents whilst 31 of them were also found to report complaints in the first category, we therefore decided to focus our analyses on the first category. An additional argument was that the complaints assembled in the first category tend to be multidimensional, and largely parallel those included in the fatigue questionnaire used by David et al. (1990) in their community study.

\section{Analysis}

The set of data contained information on not only the frequency with which fatigue was indicated as a complaint but also the chronicity of the complaint because the diary contained the item "this complaint has already lasted more than a year".

Comparative statistics were undertaken with the scores for the NCFd and CFd subjects and then repeated for each gender separately. Only those gender differences that reached statistical significance are reported here. Depending on the type of variable (interval, ordinal or nominal) t-tests, Mann-Whitney tests (U value) or Pearson's $\chi_{2}$ tests were used in conjunction with a Bonferroni Correction procedure. (When a family of items was measured, the criteria for significance were increased by dividing the required level by the total number of items involved. In such a manner, the probability of a type-I error was kept within the limits of $0.01 \%$ ). If a normal distribution could not be assumed (for example, for the checklists), the outcomes were tested with non-parametric statistics. Finally, discriminant analyses were performed to determine which combination of factors could predict the categorization of a person as $\mathrm{NCFd}$ or $\mathrm{CFd}$. 
Mens-Verhulst, J. van, Bensing, J. Distinguishing between chronic and nonchronic fatigue, the role of gender and age. Social Science \& Medicine: 1998, 47(5), p. 621-634

\section{RESULTS}

The final sample consisted of 394 men and 741 women ( $34.7 \%$ and $65.3 \%$, respectively). Among them were 380 chronically fatigued (CFd) and 755 non-chronically fatigued (NCFd) subjects $-33.5 \%$ and $66.5 \%$, respectively. The distribution of the fatigue complaints for NCFd and CFd subjects is presented in Table 1. As can be seen both intermittent and persistent patterns of complaint occurred in both of the groups.

The CFd registered significantly more fatigue days in the period of measurement than the NCFd did. In this respect the number of women within the CFd group tended to exceed the men $(\mathrm{p}=0.033)$.

\section{[TABLE 1]}

\section{Socio-demographic differences}

Drawing a distinction in terms of the duration to the fatigue revealed different sociodemographic and socio-economic profiles. An overview of the results is presented in Table 2.

Compared to the NCFd group, the age of the CFd was higher, they had fewer children under 6 , their educational level and occupational status were lower and their rate of nonemployment was higher. The men/women ratio was similar for the two groups. A few critical social characteristics nevertheless appeared to vary with gender. Within the men's sample, the occupational status for $50 \%$ of the CFd was manual worker, and they typically had compulsory health insurance which usually indicates a lower income level. Within the women's sample, the CFd were significantly more likely to be widowed or divorced than the NCFd. This difference in marital status between NCFd and CFd women seems to be largely responsible for the differences between NCFd and CFd in the general population.

\section{[TABLE 2]}

\section{Differences in well-being}

As can be seen from Table 3, CFd scored significantly higher on the GHQ and the BIOPRO than the NCFd which means that they have more psychological and psycho-social problems. Inspection of the GHQ items showed a feeling of weakness and an inability to cope with the circumstances of daily life to predominate. Inspection of the BIOPRO showed financial problems, abuse of alcohol, legal or illegal drug use, sexual problems, self-image problems and general worry to predominate. In addition, the CFd men reported loneliness more often than the NCFd men and the CFd women reported more problems with ageing, establishing relationships, worrying about the future and leisure time than the NCFd women.

The CFd and NCFd tend to differ weakly with regard to critical life events. Overall, hospitalization was at the top of the list, with $39.3 \%$ positive answers. Other predominant events were serious illness (16.4\%), death of others $(17.4 \%)$ or parents $(7 \%)$ and quitting work $(6 \%)$.

The prevalence of acute complaints and chronic diseases in the CFd group was significantly higher than in the NCFd group. This difference was parallelled by a significantly lower health experience, mood and level of daily activity. The level of wellbeing was on average lower.

\section{[TABLE 3]}

\section{Differences in health behavior}

As can be seen from Table 4 the CFd group felt more irritation and concern about their complaints, were more knowledgeable about the reason for their fatigue, and have a higher frequency of resttaking, relaxation, stopping normal activities and taking prescribed medicines. Taking prescribed medicines was the only factor to discriminate between the 
Mens-Verhulst, J. van, Bensing, J. Distinguishing between chronic and nonchronic fatigue, the role of gender and age. Social Science \& Medicine: 1998, 47(5), p. 621-634

NCFd and CFd groups in both the male and the female samples. The CFd women distinguished themselves from the NCFd women by resting considerably more.

[table 4]

\section{Gender differences within the groups of CFd and NCFd}

Tables 2 and 3 also show which variables within the CFd and NCFd samples could be observed to be gender different.

Within the NCFd group, the distribution of the ages of men and women were found to differ significantly, and particularly for those over the age of 65 (82.4\% women, $17.6 \%$ men). The educational level for the NCFd women was also significantly lower than for the NCFd men. Moreover, NCFd women scored significantly worse than NCFd men with regard to acute complaints, chronic ailments, health experience and activity level. They tend to have more psychological problems $(\mathrm{p}=0.031)$ and psycho-social problems $(\mathrm{p}=0.064)$.

The CFd and the NCFd both displayed a significant association of gender with living arrangement, marital status and non-employment. In both samples, the distribution of nonemployment significantly varied with gender. Housekeeping was mainly reported by women and retirement by men. For both $\mathrm{CFd}$ and $\mathrm{NCFd}$, the percentage of men who were married exceeded the percentage of women, and the percentage of women who were divorced or widowed exceeded the percentage of men. Men more frequently lived in a complete family or alone than women; women more frequently constituted a one-parent family than men or had not answered the question. Men tended to reduce their alcohol consumption more than women.

\section{Predictability of NCFd and CFd condition}

In Table 5, the results of successive discriminant analyses are presented. Whether someone belonged to the category of NCFd or CFd could be predicted correctly for $73 \%$ of the cases using 5 factors (in decreasing weight): chronic complaints, psycho-social problems, nonemployment, age and low educational level. The categorization of the younger subjects was predicted somewhat better than that of the older subjects, and the men's condition was better predicted than the women's.

When analyzed separately by gender, two additional factors turned out to be important: acute complaints for men, and having children under the age of six for women. When analyzed separately in two age groups, the main gender differences were found to be located in the group with the lowest age. The predictive factors for women 25-44 years did not differ from those for women in general; for men 25-44 years, non-employment was not a predictive factor although its absence did predict NCFd for older men. In the group aged 45 to 65 years, NCFd could be predicted by two common factors for both men and women: nonemployment and the GHQ-score. The first predictor for men was non-employment; the first predictor for women was the GHQ-score.

In all conditions, the predictive power of the variables was mainly for NCFd. Categorization as NCFd was accurately predicted in more than $90 \%$ of the cases while a categorization as $\mathrm{CFd}$ was found to be below chance (percentages varying from $26 \%$ to $45 \%$ ). The one exception to this was for men between 45 and 64 years of age.

\section{[TABLE 5]}

\section{DISCUSSION}

\section{Differences between CFd and NCFd people}

The CFd subjects exhibit the social profile of the disadvantaged: lower educational level, lower level of employment and income. A spiral of negative health influences can also be assumed to start from their lower educational level. 
Mens-Verhulst, J. van, Bensing, J. Distinguishing between chronic and nonchronic fatigue, the role of gender and age. Social Science \& Medicine: 1998, 47(5), p. 621-634

Inspection of the categories for non-employment reveals that men and women are dissimilar in this respect. For men the category of non-employed encompasses mainly those who are retired or disabled. This is particularly true for men categorized as CFd and may explain their lower income. For women, the category of non-employed consists mainly of housewives; their wealth tends to be low in both conditions of fatigue. Therefore, the male spiral of lower educational level, lower occupational status, non-employment, and low income is not valid for women and especially not for Dutch married women because their status mostly depends on the position of their partners. For women, nonemployment and low income are also clearly present in the NCFd condition; in the CFd condition many of them are divorced or widowed, which also may lower their socio-economic status.

CFd subjects score high on the General Health Questionnaire. This fact corresponds to the general image of people suffering from long-term fatigue as being stressed and depressed. The usual difference in GHQ scores between men and women could not be established in our study. The distinction in chronicity of fatigue seems to blur this gender difference.

The higher rate of having a chronic disease and acute complaints observed among the CFd subjects confirms the findings of earlier studies (Chen, 1986; Lewis and Wessely, 1992; Bensing et al., 1996). The higher frequency of health-related actions fits this portrait. The excess of acute complaints and chronic ailments among NCFd women agrees with the general finding of Gijsbers van Wijk (1995). However, Gijsbers van Wijk argues that the gender differences in the daily experience of physical health symptoms can be accounted for by a somatising disposition, low levels of external information, and concurrent negative mood status among women. Yet these factors cannot explain either why the NCFd men and women did not significantly differ in the number of fatigue days they register or why the CFd men and women did not significantly differ in their reporting of acute complaints or chronic ailments. One must assume that a more complex interaction between social, psychological as well as physical factors is going on which, for example, influences the possibilities for dealing with fatigue, and calls for further differentiation in the people with fatigue and associated complaints.

Some of our findings seem to counter the results of the Bensing and Schreurs (1995) survey analysis which ran parallel to our diary study. Firstly, they found the average age of fatigued people to be 35.8 and to correlate inversely with fatigue. Secondly, for the women in their sample, they established a positive association of fatigue with the presence of children under six years of age in the home. Thirdly, they concluded that fatigued men's chronic diseases were more severe than fatigued women's. However, the disagreements must be due to the absence of stratification. Their analysis did not differentiate the degree of chronicity. So, in their sample busy people in their thirties, pregnant women or recent mothers and heavily occupied parents of young children predominate the overall picture.

\section{The importance of stratification}

Our findings on the difference in profile between CFd and NCFd people, the possibility to contextualize gender differences found in earlier studies, and the outcomes of the discriminant analyses confirm the importance of stratification for chronicity. Additionally, one may conclude that the predictability of belonging to the NCFd group can be enhanced by a distinction in gender. The predictability of the CFd group can be somewhat improved by making distinctions in age and gender, but the search for relevant homogeneities within the CFd group should be continued.

The variables found to best discriminate between people categorized as CFd vs NCFd constitute a dimension with individual characteristics at the one side and social characteristics at the other. For people 25-44 years of age, the "individual" side may largely consist of psycho-social and somatic factors. In the case of men, the absence of psychosocial problems and acute complaints accompanying fatigue is most predictive; in case of women the absence of chronic complaints is most predictive. For people 45-64 years of age, the individual side consists of the absence of psychological complaints as measured by the 
Mens-Verhulst, J. van, Bensing, J. Distinguishing between chronic and nonchronic fatigue, the role of gender and age. Social Science \& Medicine: 1998, 47(5), p. 621-634

GHQ. The predictive power of this factor appears to be different for women and men: the highest and the lowest, respectively.

The "social" side seems to be more fixed for women than for men. For all women employment is a predictor of NCFd. For younger women, having no young children is an additional social predictor. And for men, the younger men's educational level appears to be replaced by non-employment as a predictor of NCFd for older men.

The gender- and age-related differences observed here shed light on our finding that $\mathrm{CFd}$ men tend to live alone more frequently than NCFd men and our finding of no such difference for CFd vs NCFd women. Younger NCFd men have few psycho-social problems, a higher education and only sporadic acute complaints. They also tend to live in more favorable conditions which might help them escape from chronic fatigue. If these conditions are less advantageous not only the probability of quick recuperation decreases but also the prospect of marriage and living in a couple or family. Younger women not hindered by any chronic diseases, psycho-social problems, non-employment or children under the age of six, are less likely to be married although they may live in a one-parent family, be divorced or widowed. For both older men and women, the absence of psychological problems and the presence of employment mainly precludes the continuation of fatigue. When these circumstances are less favorable, the chances for recovery will be lower and also correlate with the probability of living alone. This chain of events may vary in starting point for each gender and for each individual.

\section{Methodological reflections}

The outcomes of the present study should be considered tentative for several reasons. Firstly, the validity of the results may be hindered by the heterogeneity of the fatigue complaints contained in our categorization. However, this does not seem to be a major problem because our subjects apart from their scores in the diaries appeared to have scored fatigue at the top of the Symptom Check List - followed by nervousness, sleeplessness, lack of energy and headaches - which gives plausibility to the validity of the measurement. Furthermore, the answers in our study may more frequently reflect fatigue as a complaint in and of itself than as a side-e.ect of some other malady because the diary keepers were instructed to register their chief complaints - and did not tick a check list. (The prevalence of fatigue was indeed found to be lower in our diary study than in the symptom check list.) Additionally, the categorization does not allow for further differentiation between physical, mental and general fatigue. Still, the particular combination of complaints parallels the fatigue questionnaire used by David et al. (1990). Overall, the validity and reliability of the information can be considered satisfactory although our conclusions could be nuanced as to refer to fatigue and its associated symptoms.

Not only the quality of the data associated with survey studies was surpassed by the dayto-day registration of complaints, but also the drawbacks of open-ended questions were largely remedied (Verbrugge, 1980; Kooiker, 1995; Sonsbeek, 1996).

For example, the coding system could handle a mixture of complaints and medical diagnoses. Also, $80 \%$ coding agreement was achieved on average by careful training (with problem cases) and monitoring of the (para)medical field workers, although the component containing fatigue ("symptoms and complaints") was among the components with the lowest agreement (Van der Velden et al., 1992).

More generally, chronic fatigue as defined in our study cannot be equated with chronic fatigue as defined by Fukuda et al. (1994). While we applied a cut-o. point of one year, Fukuda et al. employed six months. This means an unknown part of our NCFd would belong to their group of chronically fatigued and thus makes comparison most difficult. Secondly, the checklists with regard to acute complaints, chronic diseases, critical life events and psycho-social problems should be more thoroughly validated. As checklists tend to report a greater number of symptoms, are particularly sensitive to psychological distress (Kooiker, 1995), and slight differences in wording can produce major differences (Van der Velden et 
Mens-Verhulst, J. van, Bensing, J. Distinguishing between chronic and nonchronic fatigue, the role of gender and age. Social Science \& Medicine: 1998, 47(5), p. 621-634

al., in press), the correlations established here must be replicated in future studies. According to Sonsbeek (1996) comparable lists all indicate a quite physical accent. From the perspective of fatigue, it is a pity that the checklist for chronic diseases does not include some other interesting conditions - such as low blood pressure, severe anaemia and AIDS. Similarly, the type of cancer and its seriousness are not specified.

Thirdly, it may be asked whether the population investigated here is sufficiently representative to justify the conclusions with regard to differences in age and education. Using diaries for the assessment of health status means running risks of under-representation of disadvantaged groups such as elderly or poorly educated (Kooiker, 1995). It can nevertheless be argued that a more adequate instrument will only produce stronger associations than found here.

Fourthly, the conclusions with regard to healthrelated actions should be considered preliminary because some actions may be undertaken in response to complaints in a category other than fatigue. Moreover, the findings with regard to (non)employment must be interpreted with some caution because people falling in this category were not found to report their employment status consistently in the diary and survey part of the study.

Fifthly, differences that were not established cannot be considered non-existent. As level of significance selected for our tests of physical, psychological, psycho-social and socioeconomic differences was 0.01 , the chances of accepting unjustified differences were very low, and the chances of overlooking existing differences rather high.

Finally, it should be mentioned that the data were gathered in 1987-88. Therefore, a cohort-e.ect must be accounted for. Presumably, the importance of chronicity, age and gender as variables for stratification have not changed, but rather the profiles which become visible after differentiation. This is especially true with regard to genderbound predictors because the social position of Dutch women is gradually changing. Nowadays they participate in the labor force more often (in particular the younger women) and the child care facilities for children under the age of 6 have been improved somewhat. Simultaneously the number of couples without children is on the increase (Hooghiemstra and Niphuis-Nell, 1993; Hooghiemstra, 1997). So, more recent data are needed for further study.

All in all, this study may slightly underestimate the level of depression-related fatigue by our decision to limit our investigation to the first fatigue category. The contrasts between CFd and NCFd with regard to psychological and psycho-social problems may be underestimated as well. These methodological flaws, however, do not undermine the conclusions. People su.ering from chronic fatigue are multiply vulnerable: physical, psychological, psycho-social and socio-economic factors may all contribute to chronic fatigue. Besides, stratification for socio-demographic factors is useful.

Physicians should approach their fatigued patients in terms of gender and age. Possible differences in etiology may require different recommendations and/or prescriptions. In such a manner a nasty spiral into greater fatigue and despair can be prevented.

Acknowledgements -This study could only be carried out with the data so graciously provided by the Netherlands' Institute for Primary Health Care (NIVEL).

\section{REFERENCES}

Adesso, V. J., Reddy, D. M. and Fleming, R. (1994) Psychological perspectives on women's health: an introduction and overview. In Psychological Perspectives on Women's Health. Taylor and Francis, Washington.

Bakker, D. de, Claessens, A. and Van der Velden, K. (1992) Man-vrouw verschillen in gezondheid en medische consumptie. Nationale studie van ziekten en verrichtingen in de huisartspraktijk. NIVEL, Utrecht.

Bensing, J. M. and Schreurs, K. (1995) Sekseverschillen by moeheid. Huisarts en Wetenschap 38, 412-421. 
Mens-Verhulst, J. van, Bensing, J. Distinguishing between chronic and nonchronic fatigue, the role of gender and age. Social Science \& Medicine: 1998, 47(5), p. 621-634

Bensing, J. M., Hulsman, R. and Schreurs, K. (1996) Vermoeidheid; een chronisch probleem. Medisch contact 51, 123-124.

Brown, J. S. and Rawlinson, M. E. (1977) Sex differences in sick role rejection and in work performance following cardiac surgery. Journal of Health and Social Behavior 18, 276-292.

Chalder, T., Berelowitz, G., Pawlikowska, T., Watts, L., Wessely, S., Wright, D. and Wallace, E. P. (1993) Development of a fatigue scale. Journal of Psychosomatic Research 17, 147153.

Chen, M. K. (1986) The epidemiology of self-perceived fatigue among adults. Preventive Medicine 15, 74-81.

Cox, B., Blaxter, M., Buckle, A. et al. (1987) The Health and Lifestyle Survey. Health Promotion Trust, London.

David, A., Pelosi, A., Mc Donald, E., Stephens, D., Ledger, D., Rathbone, R. and Mann, A. (1990) Tired, weak, or in need of rest: fatigue among general practice attenders. British Medical Journal 301, 1191-1202.

Foets, M. and Sixma, H. (1991) Een Nationale studie van ziekte en verrichtingen in de huisartspraktijk. Basisrapport gezondheid en gezondheidsgedrag in de praktijkpopulatie. NIVEL, Utrecht.

Foets, M. and Van der Velden, J. (1990) Nationale studie naar ziekten en verrichtingen in de huisartspraktijk. Basisrapport: Meetinstrumenten en procedures. NIVEL, Utrecht.

Foets, M., Van der Velden, J. and De Bakker, D. (1992) Dutch National Survey of General Practice. A Summary of the Survey Design. NIVEL, Utrecht.

International Chronic Fatigue Syndrome Study Group Fukuda, K., Straus, S. E., Hickie, I., Sharpe, M. C., Dobbins, J. G. and Komaro., A. (1994) The chronic fatigue syndrome: a comprehensive approach to its definition and study. Annals of Internal Medicine 121, 953959.

Furer, J. W. and Tax, B. (1987) Somatische klachten, psychiatrische symptomen en psychosociale problemen. Instituut voor Sociale Geneeskunde, KUN, Nijmegen.

Gijsbers van Wijk, C. M. T. (1995). Sex differences in symptom perception. Thesis, UvA, Amsterdam.

Gijsbers van Wijk, C. M. T., Kolk, A. M. M., Van den Hoogen, H. J. M. and Van den Bosch, W. H. J. M. (1995) Male and female health problems in general practice: The differential impact of social position and social role. Social Science and Medicine 40, 597-611.

Goldberg, D. P. (1972) The Detection of Psychiatric Illness by Questionnaire. Oxford University Press, London.

Goldberg, D. (1978) Manual of the General Health Questionnaire. NFER Publishing Company, Windsor.

Hooghiemstra, B. T. J. (1997) Demografische ontwikkelingen. In Sociale atlas van de Vrouw. Deel 4. Veranderingen in de Primaire Leefsfeer, ed. NiphuisNell, Sociaal Cultureel Planbureau, Den Haag.

Hooghiemstra, B. T. J. and Niphuis-Nell, M. (1993) Sociale atlas van de vrouw. Deel 2. Arbeid, inkomen en faciliteiten om werken en de zorg voor kinderen te combineren. Sociaal Cultureel Planbureau, Den Haag.

Kirk, J., Douglass, R., Nelson, E., Ja.e, J., Lopez, A., Ohier, J., Blanchard, C., Chapman, R., McHugo, G. and Stone, K. (1990) Chief complaint of fatigue: A prospective study. Journal of Family Practice 30, 33-39.

Knottnerus, J. A., Knipschild, P. G., Van Wersch, J. W. J. and Sijstermanns, A. H. J. (1986) Unexplained fatigue and hemoglobin. A primary care study. Canadian Family Physician 32, 1601-1604.

Kooiker, S. E. (1995) Exploring the iceberg of morbidity: a comparison of different survey methods for assessing the occurrence of everyday illness. Social Science and Medicine 41, 317-332.

Kooiker, S. (1996) Illness in everyday life. A health diary study of common symptoms and their consequences. Thesis, NIVEL, Utrecht.

Kroenke, K., Wood, D. R. and Mangelsdor., A. D. et al. (1988) Chronic fatigue in primary care. Prevalence, patient characteristics and outcome. JAMA 2609, 929- 934.

Lamberts, H. (1991) In het huis van de huisarts. Meditekst, Lelystad.

Lamberts, H. and Wood, M. (ed.) (1987) The International Classification of Primary Care. Oxford, University Press, Oxford. 
Mens-Verhulst, J. van, Bensing, J. Distinguishing between chronic and nonchronic fatigue, the role of gender and age. Social Science \& Medicine: 1998, 47(5), p. 621-634

Lawrie, S. M. and Pelosi, A. J. (1995) Chronic Fatigue Syndrom in the community. Prevalence and associations. British Journal of Psychiatry 166, 793-797.

Leventhal, E. A. (1994) Gender, health and ageing. In Psychological Perspectives on Women's Health. ed. V. J. Adesso, D. M. Reddy and R. Fleming. Taylor and Francis, Washington.

Lewis, G. and Wessely, S. (1992) The epidemiology of fatigue: more questions than answers. Journal of Epidemiology and Community Health 46, 92-97.

Van de Lisdonk, E. H. (1985) Ervaren en aangeboden morbiditeit in de huisartspraktijk. Thesis, KUN, Nijmegen.

Van Mens-Verhulst, J. and Bensing, J. M. (1997) Sex differences in persistent fatigue. Women and Health 26(3), 51-70.

Morrison, J. (1980) Fatigue as a presenting complaint in family practice. Journal of Family Practice 10, 795-801.

Pawlikowska, T., Chalder, T., Hirsch, S. R., Wallace, P., Wright, D. J. M. and Wessely, S. C. (1994) Population based study of fatigue and psychological distress. British Medical Journal 308, 763-766.

Pennincks, H. K. M. (1991) Epidemiologische gegevens en filosofische overwegingen over de klacht moeheid. Bijblijven 7, 4-8.

Ray, C., Weir, W. R. C., Phillips, S. and Cullen, S. (1992) Development of a measure of symptoms in chronic fatigue syndrome: The profile of fatigue-related symptoms (PFRS). Psychology and Health 7, 27-43.

Ridsdale, L., Evans, A., Jerrett, W., Mandalia, S., Osler, K. and Vora, H. (1993) Patients with fatigue in general practice: a prospective study. British Medical Journal 307, 103-106.

Smets, M. A., Garssen, B., Bonke, B. and De Haes, J. C. M. (1995) The multidimensional fatigue inventory (MFI). Psychometric qualities of an instrument to assess fatigue. Journal of Psychosomatic Research 39, 315-325.

Sonsbeek, J. L. A. (1996) Vertel me wat er aan scheelt. Betekenis en methodische aspecten van enquetevragen naar de gezondheid. Thesis, KUN, Nijmegen.

Sugarman, J. R. and Berg, A. O. (1984) Evaluation of fatigue in a family fractice. Journal of Family Practice 19, 643-647.

Tibblin, G., Bengtsson, C., Furunes, B. and Lapidus, L. (1990) Symptoms by age and sex. The population studies of men and women in Gothenburg, Sweden. Scandinavian Journal of Primary Health Care 8, 9-17.

Tijhuis, M. A. R. (1994). Social networks and health. Thesis, NIVEL, Utrecht.

Tijhuis, M. A. R., Verhaak, P. F. M. and Wennink, H. J. (1991) Psychosociale problemen in de huisartspraktijk.NIVEL, Utrecht.

Valdini, A., Steinhardt, S. and Ja.e, A. (1987) Demographic correlates of fatigue in a university family health centre. Journal of Family Practice 4, 103-107.

Valdini, A., Steinhardt, S., Valiventi, J. and Ja.e, A. (1988) A one-year follow-up of fatigued patients. Journal of Family Practice 26, 33-38.

Van den Bos, G. A. M., Mohrs, J., Habbema, J. D. F., Van der Maas, P. J. et al. (1986) Chronische aandoeningen, hulpbehoevendheid en zorggebrek. ISG, Amsterdam, and IMG, Rotterdam.

Van der Velden, J., De Bakker, D. H., Claessens, A. A. M. C. and Schellevis, F. G. (1992) Dutch National Survey of General Practice. Morbidity in General Practice. NIVEL, Utrecht.

Van der Velden, L., Abrahamse, H. Ph. H., Donker, G. and Van der Steen, J. (in press) What are health interview surveys telling us about the prevalence of domatic chronic diseases. European Journal of Public Health.

Verbrugge, L. M. (1980) Health diaries. Medical Care 18, 73-95.

Vereijken, I. and Bauduin, D. (1992) Social klasse, sekse en psychische problemen. NcGv, Utrecht.

Vermande, M. and Bijl, R. (1995) Psychische problematiek in Nederland. NcGv, Utrecht.

Vertommen, H. and Leyssen, N. J. (1988) Vermoeidheid: van onhanteerbaar symptoom tot diagnostisch waardevolle gezondheidstoestand. Tijdschrift voor Klinisch Psychologie 18, 35-59. 
Mens-Verhulst, J. van, Bensing, J. Distinguishing between chronic and nonchronic fatigue, the role of gender and age. Social Science \& Medicine: 1998, 47(5), p. 621-634

FIGURES AND TABLES

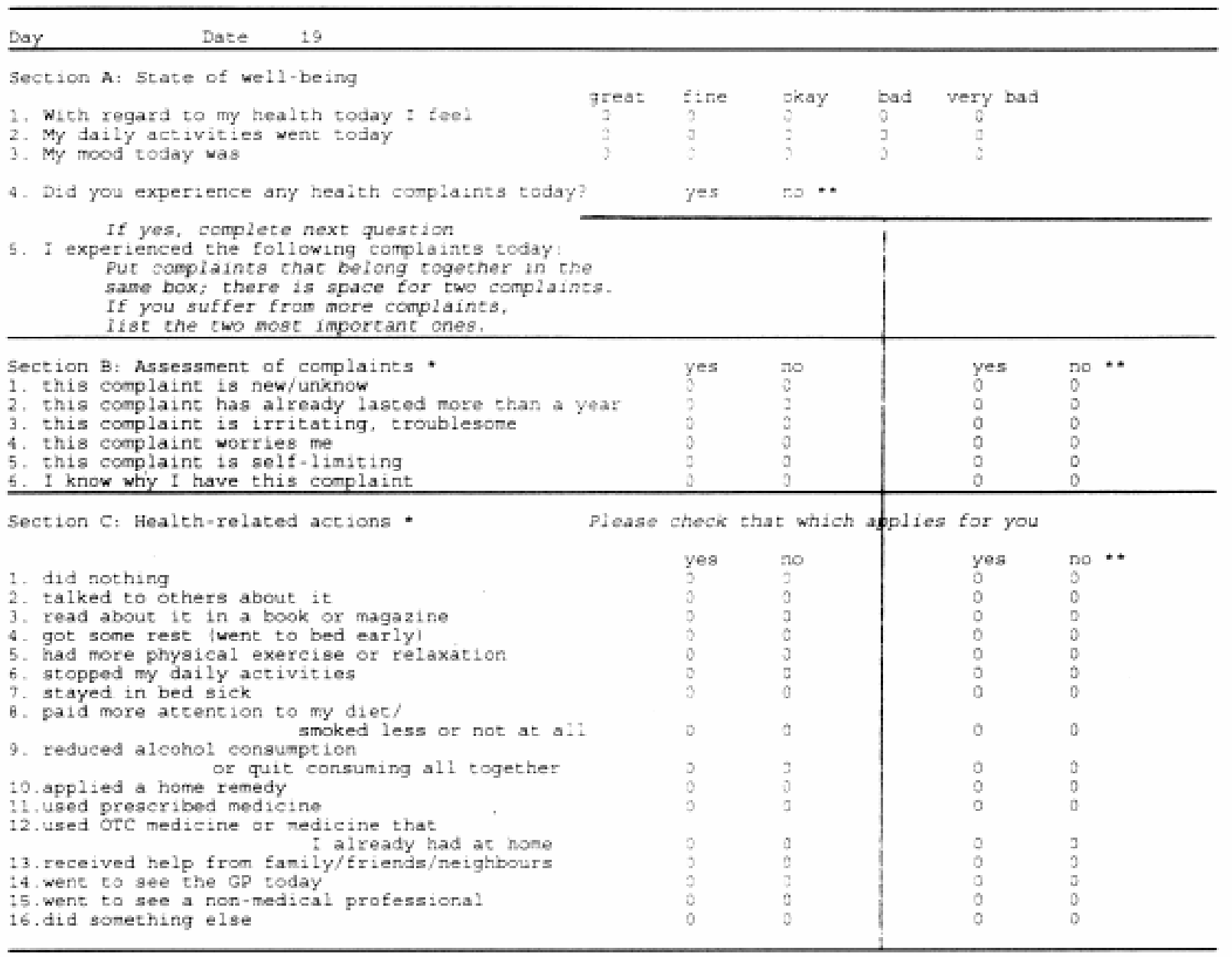

- These lists could be filied in for two clusters of complaincs

* Only the first list of answers was filied in properly and couid be used for analysis.

Fig. 1. Sample page from the health diary

days with

\begin{tabular}{|c|c|c|c|c|c|c|c|c|c|c|}
\hline 1 & 466 & 41.1 & 371 & 49.1 & 34.2 & 65.8 & 95 & 25.0 & 30.5 & 69.5 \\
\hline 2 & 265 & 23.3 & 182 & 24.1 & 38.5 & 61.5 & 83 & 21.8 & 36.1 & 63.9 \\
\hline 3 & 116 & 10.2 & 67 & 8.9 & 35.8 & 64.2 & 49 & 12.9 & 37.7 & 67.3 \\
\hline 4 & 75 & 6.6 & 45 & 6.0 & 28.9 & 71.1 & 30 & 7.9 & 23.3 & 76.7 \\
\hline 5 & 55 & 4.8 & 25 & 3.3 & 16.0 & 84.0 & 30 & 7.9 & 90.0 & 50.0 \\
\hline 6 & 37 & 3.3 & 18 & 2.4 & 38.9 & 61.1 & 19 & 5.0 & 42.1 & 57.9 \\
\hline 7 & 24 & 2.1 & 14 & 1.9 & 42.9 & 57.1 & 10 & 2.6 & 20.0 & 80.0 \\
\hline 8 & 11 & 1.0 & 4 & 0.5 & 0.0 & 100.0 & 7 & 1.8 & 14.3 & 85.7 \\
\hline 9 & 11 & 1.0 & 3 & 0.4 & 0.0 & 1000 & 8 & 2.1 & 25.0 & 750 \\
\hline 10 & 6 & 0.5 & 2 & 0.3 & 90.0 & 50.0 & 4 & 1.1 & 50.0 & 500 \\
\hline 11 & 6 & 0.5 & 4 & 0.5 & 25.0 & 75.0 & 2 & 0.5 & 0.0 & 100.0 \\
\hline 12 & 5 & 0.4 & 2 & 0.3 & 100.0 & 0.0 & 3 & 0.8 & 33.3 & 66.7 \\
\hline 13 & 5 & 0.4 & 1 & 0.1 & 0.0 & 1000 & 4 & 1.1 & 25.0 & 750 \\
\hline 14 & 5 & 0.4 & 2 & 0.3 & 0.0 & 1000 & 3 & 0.8 & 33.3 & 66.7 \\
\hline 15 & 4 & 0.4 & 0 & & & & 4 & 1.1 & 90.0 & 50.0 \\
\hline 16 & 3 & 0.3 & 0 & & & & 3 & 0.8 & 33.3 & 66.7 \\
\hline 17 & 7 & 0.6 & 4 & 0.5 & 25.0 & 75.0 & 3 & 0.8 & 66.7 & 33.3 \\
\hline 18 & 1 & 0.1 & 0 & & & & 1 & 0.3 & 0.0 & 1000 \\
\hline 19 & 8 & 0.7 & 4 & 0.5 & 75.0 & 250 & 4 & 1.1 & 25.0 & 750 \\
\hline 20 & 8 & 0.7 & 2 & 0.3 & 0.0 & 100.0 & 6 & 1.6 & 90.0 & 50.0 \\
\hline 21 & 17 & 1.5 & 5 & 0.7 & $\$ 0.0$ & 60.0 & 12 & 3.2 & 75.0 & 250 \\
\hline & \multicolumn{3}{|c|}{$100 \%$} & $100 \%$ & \multicolumn{6}{|c|}{$100 \%$} \\
\hline
\end{tabular}




\begin{tabular}{|c|c|c|c|c|c|c|c|c|c|c|c|c|c|c|c|}
\hline & $\begin{array}{c}\text { NCF, } \\
N-755 \\
\text { (mean) }\end{array}$ & $\begin{array}{c}\mathrm{CF}, \\
N-380 \\
\text { (mean) }\end{array}$ & $t$-value & df & $P$ & $\begin{array}{l}\text { NCF men, } \\
N=261 \\
\text { (mean) }\end{array}$ & $\begin{array}{c}C F \text { men, } \\
N-133 \\
\text { (mean) }\end{array}$ & $t$-value & df & $P$ & $\begin{array}{c}\mathrm{NCF} \\
\text { women, } \\
N=494 \\
\text { (mean) }\end{array}$ & $\begin{array}{c}\text { CF women, } \\
N=247 \\
\text { (mean) }\end{array}$ & $t$-value & $\mathrm{df}$ & $P$ \\
\hline \multirow[t]{2}{*}{ Age } & • & & & & & & & & & & & & & & \\
\hline & $\begin{array}{l}41.54 \\
\text { Perc }\end{array}$ & $\begin{array}{l}47.74 \\
\text { Perc }\end{array}$ & -7.20 & 756.42 & $<0.001$ & $\begin{array}{l}40.23 \\
\text { Perc }\end{array}$ & $\begin{array}{c}48.91 \\
\text { Perc }\end{array}$ & -7.02 & 392 & $<0.001$ & $\begin{array}{l}42.25 \\
\text { Perc }\end{array}$ & $\begin{array}{l}47.12 \\
\text { Perr }\end{array}$ & -4.32 & 504.55 & $<0.001$ \\
\hline $25-44$ & 67.4 & 45.8 & & & & 71.6 & 39.8 & & & & 65.2 & 49.0 & & & \\
\hline \multirow{3}{*}{$>64$} & 23.6 & 40.8 & & & & 23.8 & 47.4 & & & & 23.5 & 37.2 & & & \\
\hline & 10.0 & 13.4 & & & & 4.6 & 12.8 & & & & 11.3 & 13.8 & & & \\
\hline & Perc & Perc & $C_{i 2}$ & & & Perc & Perc & $\operatorname{Ch} 2$ & & & Perc & Perc & $\mathrm{Ch} 22$ & & \\
\hline Children under 6 & 27.6 & 15.61 & 17.50 & 1 & $<0.001$ & 27.3 & 14.8 & 6.90 & 1 & 0.009 & 27.8 & 16.1 & 10.65 & 1 & 0.001 \\
\hline Hedith ŷsuratice & & & 6.68 & 1 & 0.010 & & & 6.30 & 1 & 0.012 & & & 2.09 & 1 & 0.154 \\
\hline compulsory & 60.1 & 68.1 & & & & 51.4 & 649 & & & & 64.6 & 70.0 & & & \\
\hline private & 39.9 & 31.9 & & & & 48.6 & 35.1 & & & & 35.4 & 30.0 & & & \\
\hline Living Arrangement & $*$ & $\therefore$ & 7.49 & 3 & 0.058 & & & 8.88 & 3 & 0.031 & & & 4.54 & 3 & 0.209 \\
\hline living abo ne & 24.0 & 29.7 & & & & 26.2 & 34.4 & & & & 22.9 & 27.0 & & & \\
\hline family/ooupk & 57.8 & 49.2 & & & & 65.4 & 52.3 & & & & 53.8 & 47.3 & & & \\
\hline one perent houxhold & 4.7 & 6.2 & & & & 2.1 & 0.8 & & & & 6.1 & 9.3 & & & \\
\hline missing & 13.5 & 15.0 & & & & 6.3 & 12.5 & & & & 17.3 & 16.4 & & & \\
\hline Marital status & $\bullet$ & $* *$ & 10.8 & 2 & 0.005 & & & 0.60 & 2 & 0.740 & & & 12.12 & 2 & 0.002 \\
\hline single & 15.7 & 13.2 & & & & 15.8 & 16.3 & & & & 15.6 & 11.4 & & & \\
\hline married & 75.1 & 70.9 & & & & 80.4 & 78.3 & & & & 72.3 & 66.7 & & & \\
\hline wid owed or divored & 9.3 & 16.0 & & & & 3.8 & 5.4 & & & & 12.1 & 21.9 & & & \\
\hline
\end{tabular}

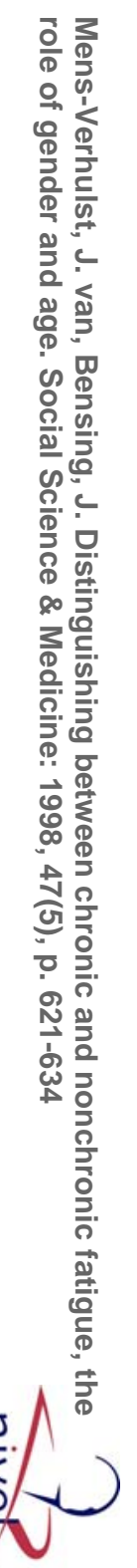




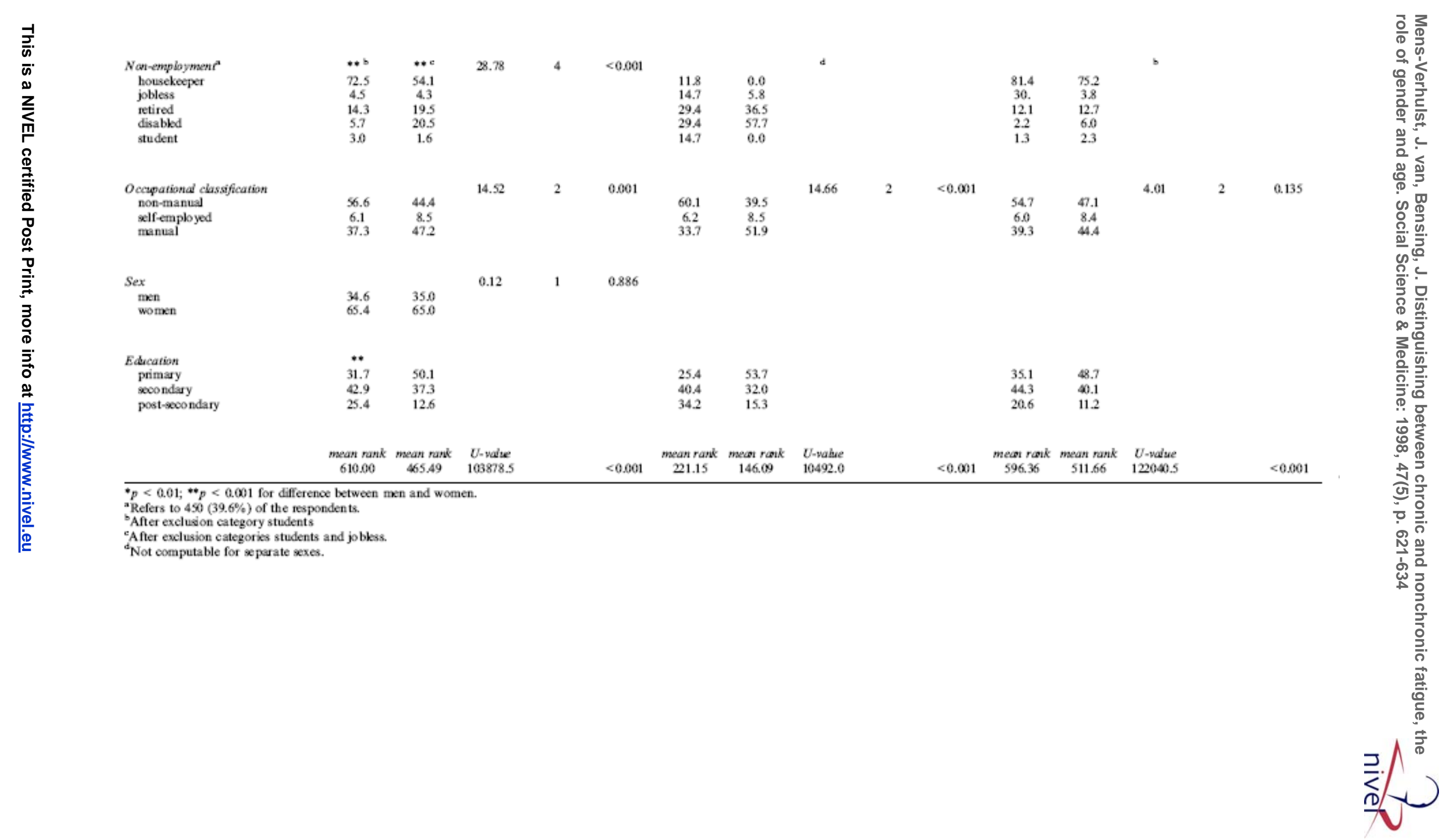


Table 3. Differenoes between NCF and CF men and women in psychobgieal and psycho-social problems and in physical and general well-being

\begin{tabular}{|c|c|c|c|c|c|c|c|c|c|c|c|c|c|c|c|c|c|c|}
\hline & \multicolumn{2}{|c|}{ NCF } & \multicolumn{2}{|c|}{$\mathrm{CF}$} & \multirow[t]{2}{*}{$t$-value } & \multirow[t]{2}{*}{$P$} & \multicolumn{2}{|c|}{ NCF-men } & \multicolumn{2}{|c|}{$\mathrm{CF}$} & \multirow[t]{2}{*}{$t$-value } & \multirow[t]{2}{*}{$P$} & \multicolumn{2}{|c|}{ NCF women } & \multicolumn{2}{|c|}{ CF women } & \multirow[t]{2}{*}{$t$-value } & \multirow[t]{2}{*}{$P$} \\
\hline & mean & SE & mean & SE & & & mean & SE & mean & SE & & & mean & SE & mean & SE & & \\
\hline $\begin{array}{l}\text { Psychobogical } \\
\text { problems (GHQ-30) }\end{array}$ & 2.95 & 0.183 & 5.07 & 0.351 & -5.92 & ** & 2.41 & 0.284 & 4.92 & 0.584 & -4.33 & ** & 3.24 & 0.235 & 5.16 & 0.440 & -4.22 & ** \\
\hline $\begin{array}{l}\text { Psyeho-sacial } \\
\text { problems (BIOPRO) }\end{array}$ & 1.24 & 0.041 & 1.81 & 0.057 & -8.12 & $* *$ & 1.13 & 0.069 & 1.83 & 0.096 & -5.90 & ** & 1.30 & 0.051 & 1.81 & 0.072 & -5.76 & ** \\
\hline Life events & 1.07 & 0.063 & 1.35 & 0.089 & -2.47 & * & 0.92 & 0.114 & 1.16 & 0.157 & -1.23 & & 1.16 & 0.076 & 1.45 & 0.108 & -2.20 & \\
\hline $\begin{array}{l}\text { Acute complaints } \\
\text { (without fatigue) }\end{array}$ & 3.09 & $0.166^{\prime ي}$ & 5.30 & 0.316 & -6.85 & "* & 2.06 & 0.227 & 4.34 & 0.451 & -5.05 & ** & 3.62 & 0.219 & 5.82 & 0.418 & -5.12 & ** \\
\hline Chronic diseases & & " & & & & & & & & & & & & & & & & \\
\hline total & 0.62 & 0.046 & 1.49 & 0.104 & -8.91 & $* *$ & 0.45 & 0.065 & 1.16 & 0.154 & -5.03 & $*$ & 0.71 & 0.060 & 1.67 & 0.136 & -7.46 & $*$ \\
\hline moderate & 0.18 & 0.018 & 0.51 & 0.047 & -7.98 & $\ddot{*}$ & 0.14 & 0.025 & 0.36 & 0.065 & -3.85 & $*$ & 0.20 & 0.024 & 0.99 & 0.063 & -7.04 & $*$ \\
\hline severe & 0.12 & 0.016 & 0.33 & 0.036 & -6.31 & ** & 0.12 & 0.027 & 0.38 & 0.065 & -4.40 & "* & 0.12 & 0.019 & 0.31 & 0.042 & -4.55 & $*$ \\
\hline \multicolumn{19}{|l|}{ Well-being } \\
\hline heal th experienoe & 2.13 & $0.014^{*}$ & 2.41 & 0.023 & -10.91 & $\because *$ & 2.07 & 0.025 & 2.42 & 0.041 & -7.70 & $\because *$ & 2.16 & 0.017 & 2.41 & 0.029 & -7.88 & $*$ \\
\hline $\operatorname{mood}$ & 2.08 & 0.013 & 2.30 & 0.021 & -9.70 & $* *$ & 2.05 & 0.022 & 2.33 & 0.039 & -6.72 & $* *$ & 2.09 & 0.016 & 2.30 & 0.025 & -7.07 & $* *$ \\
\hline activity kvel & 2.16 & $0.014^{*}$ & 2.38 & 0.022 & -8.38 & $* *$ & 2.11 & 0.022 & 2.37 & 0.041 & -6.29 & ** & 2.19 & 0.017 & 2.38 & 0.027 & -6.15 & $*$ \\
\hline
\end{tabular}


Mens-Verhulst, J. van, Bensing, J. Distinguishing between chronic and nonchronic fatigue, the role of gender and age. Social Science \& Medicine: 1998, 47(5), p. 621-634

Table 4. Differences in dealing with fatigue complaints between NCFs and CFs

\begin{tabular}{|c|c|c|c|c|}
\hline & $U$-value & $P$ & NCF (mean rank) & $\mathrm{CF}$ (mean rank) \\
\hline \multicolumn{5}{|c|}{ Assessnent } \\
\hline Feels intitation & 81131.5 & $*$ & 485 & 732 \\
\hline men & 9105 & $*$ & 165 & 259 \\
\hline women & 35758 & $*$ & 319 & 473 \\
\hline Feels concent & 99120 & $* *$ & 909 & 684 \\
\hline men & 11305 & $*$ & 174 & 243 \\
\hline women & 43452 & $*$ & 335 & 442 \\
\hline Knows reason & 107721 & $*$ & 520 & 662 \\
\hline men & 11901 & $*$ & 176 & 238 \\
\hline women & 47690 & $*$ & 344 & 424 \\
\hline & $U$-value & $P$ & NCF (mean) & $\mathrm{CF}$ (man) \\
\hline \multicolumn{5}{|c|}{ Healhh-related actians } \\
\hline Restîng mare & 117996.5 & $*$ & 2.25 & 3.61 \\
\hline men & 15267.5 & & 1.96 & 2.87 \\
\hline women & 48288.5 & $*$ & 2.40 & 4.02 \\
\hline More exercise/relaxation & 124474.5 & $* *$ & 0.99 & 1.26 \\
\hline men & 14796.5 & & 0.74 & 1.27 \\
\hline women & 53388.0 & $*$ & 0.51 & 1.25 \\
\hline Stop nomal activities & 1268230 & $*$ & 0.65 & 1.03 \\
\hline men & 14616.5 & & 0.99 & 1.27 \\
\hline women & 55441.5 & & 0.68 & 0.91 \\
\hline Reduce alcohol consumption & 1325110 & & 0.58 & 1.28 \\
\hline men & 14987.5 & $*$ & 0.88 & $1.92^{\mathrm{a}}$ \\
\hline women & 58332.5 & & 0.43 & 0.94 \\
\hline Take prescribed medicines & 111369.5 & $*$ & 1.07 & 3.48 \\
\hline men & 12738.5 & $*$ & 0.93 & 3.78 \\
\hline women & 48736.5 & $*$ & 1.15 & 3.31 \\
\hline
\end{tabular}

$p<0.01 ; * *<0.001$ after Bonferroni Correction Procedure.

aSignificant difference between men and women. 
Mens-Verhulst, J. van, Bensing, J. Distinguishing between chronic and nonchronic fatigue, the role of gender and age. Social Science \& Medicine: 1998, 47(5), p. 621-634

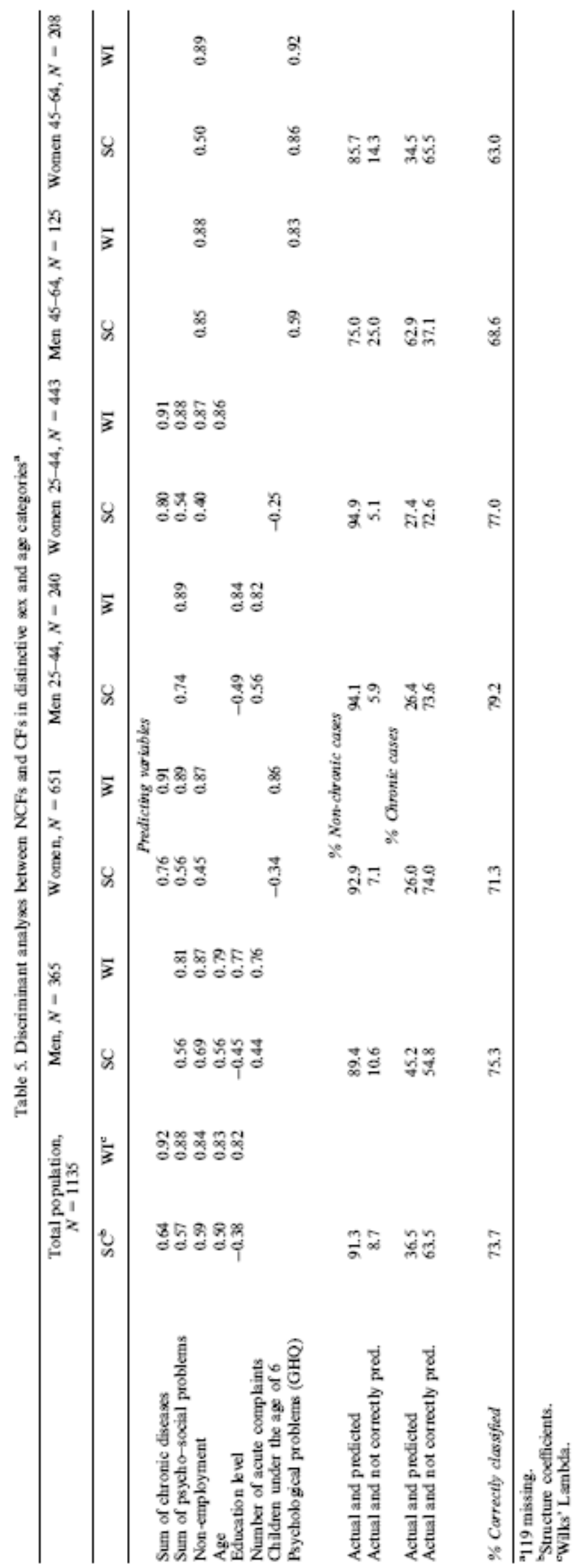

